\title{
Field Test on Electro-Osmosis in a Heavy Metal Contaminated Soil: Electrokinetic Remediation and Reinforcement of the soil
}

\author{
Junchao Zang ${ }^{1,2}$, Wenjun Wang ${ }^{2 *}$, Zhongjin Wang ${ }^{2}$, Lingwei Zheng ${ }^{1,2}$, Xinyu Xie ${ }^{1,2,}$ \\ ${ }^{1}$ Research Center of Coastal and Urban Geotechnical Engineering, Zhejiang University, Hangzhou \\ 310058, P. R.China; \\ ${ }^{2}$ Ningbo Institute of Technology, Zhejiang University, Ningbo 315100, P. R.China \\ *E-mail: wwjcumt@,nit.net.cn
}

doi: $10.20964 / 2020.02 .07$

Received: 22 June 2019 / Accepted: 14 November 2019 / Published: 31 December 2019

\begin{abstract}
With the acceleration of urbanization, less land is available for the direct construction of infrastructure. The reuse of landfills can provide resources in this respect; however, this approach requires the simultaneous removal of heavy metal ions and the strengthening of foundation. In this study, Ningbo's landfill was selected as a field test site. The concentrations of five heavy metal elements $(\mathrm{Cu}, \mathrm{Zn}, \mathrm{Pb}, \mathrm{Cd}$, $\mathrm{Cr}$ ) gradually decrease with depth. Fulvic acid can complex with heavy metal salts to form a stable soluble conjugate, which greatly improves the electric repair effect. The removal rate of heavy metals after electrokinetic remediation is approximately $25 \%-35 \%$. The heavy metal removal effect of the F2 test group was the best. The anode settlement of each group of experiments is approximately $12 \%$ larger than the cathode settlement.
\end{abstract}

Keywords: Electrokinetic remediation; Pore water pressure; Landfill test; Reinforcement

\section{$\underline{\text { FULL TEXT }}$}

(C) 2020 The Authors. Published by ESG (www.electrochemsci.org). This article is an open access article distributed under the terms and conditions of the Creative Commons Attribution license (http://creativecommons.org/licenses/by/4.0/). 